\title{
Incidence of pathologic postobstructive diuresis after resolution of ureteropelvic junction obstruction with a normal contralateral kidney
}

\author{
Joshua D. Roth, M.D. ${ }^{1}$ \\ Jeffrey D. Lesier, M.D., M.P.H. ${ }^{2}$ \\ Jessica T. Casey, M.D. ${ }^{1}$ \\ Konrad M. Szymanski, M.D., M.P.H ${ }^{1}$ \\ Benjamin M. Whittam, M.D., M.S. ${ }^{1}$ \\ Rosalia Misseri, M.D. ${ }^{1}$ \\ Richard C. Rink, M.D. ${ }^{1}$ \\ Mark P. Cain, M.D. ${ }^{1}$
}

1. Division of Pediatric Urology, Riley Hospital for Children, Indiana University School of Medicine, 705 Riley Hospital Drive, Suite 4230, Indianapolis, IN, 46202

2. Department of Pediatrics, Division of Pediatric Nephrology and Hypertension, 699 Riley Hospital Drive, Suite 230, Indianapolis, IN, 46202

This is the author's manuscript of the article published in final edited form as:

Roth, J. D., Lesier, J. D., Casey, J. T., Szymanski, K. M., Whittam, B. M., Misseri, R., ... Cain, M. P. (2018). Incidence of pathologic postobstructive diuresis after resolution of ureteropelvic junction obstruction with a normal contralateral kidney. Journal of Pediatric Urology. 


\section{Summary:}

Introduction: Postobstructive diuresis (POD) after unilateral pyeloplasty or percutaneous nephrostomy tube (PCN) insertion for ureteropelvic junction obstruction (UPJO) in patients with a normal contralateral kidney is not well described.

Objective: We sought to determine the incidence and characteristics of POD after relief of unilateral UPJO with a normal contralateral kidney.

Study Design: We retrospectively reviewed children who underwent a unilateral pyeloplasty or PCN for UPJO from 2010 to 2017 with a normal contralateral kidney. POD was defined as urine output (UOP) of $>300 \%$ of expected urine output. We excluded patients with a solitary kidney, or those who underwent bilateral pyeloplasty or bilateral PCN placement.

Results: Out of 396 children meeting inclusion criteria, 7 (1.8\%) developed POD (4 after pyeloplasty and 3 after PCN placement). Median age at intervention was 1.7 years (range 11 days - 18 years); median weight was $11.4 \mathrm{~kg}$ (range 3.7 - $54.2 \mathrm{~kg}$ ). POD was more likely in grade 4 hydronephrosis (3.0\%), larger kidneys and if a PCN was placed prior to pyeloplasty. There was no significant difference in age, gender, kidney laterality or function between those who developed POD and those who did not.

POD was managed with additional intravenous fluids and electrolyte monitoring. Median initial post-procedure UOP was $5.9 \mathrm{mg} / \mathrm{kg} / \mathrm{hr}$ (range $3.2-10.0 \mathrm{mg} / \mathrm{kg} / \mathrm{hr}$ ). In 5 children 
with PCN where UOP could be differentiated between kidneys, median initial postprocedure UOP from the affected side was $6.1 \mathrm{mg} / \mathrm{kg} / \mathrm{hr}$ (range $2.5-9.1 \mathrm{mg} / \mathrm{kg} / \mathrm{hr}$ ) and $0.8 \mathrm{mg} / \mathrm{kg} / \mathrm{hr}$ (range $0.4-0.9 \mathrm{mg} / \mathrm{kg} / \mathrm{hr}$ ) from the unaffected side. The median length of time to resolution of POD was 3 days (range 2-4 days). One patient developed significant acidosis and lethargy that improved with intravenous fluid management. Mild hyponatremia developed in 2, hypokalemia in 1, hypophosphatemia in 1, acidosis in 1 and hypoglycemia in 1 .

Discussion: We describe a low but clinically significant risk of POD occurring after relief of unilateral UPJO in children with a normal contralateral kidney. Limitations include retrospective analysis and small sample size due to the rarity of the condition.

Conclusion: POD after decompression of UPJO in patients with a normal contralateral kidney is a rare event (1.8\%). However, POD does occur, and patients should be carefully monitored following these procedures given the potential for significant dehydration and electrolyte disturbances.

Table: Factors Impacting Post Obstructive Diuresis

\section{Introduction:}

Post-obstructive diuresis (POD), defined as a period of polyuria after relief of urinary tract obstruction, is rare but well recognized phenomenon after release of bilateral ureteral obstruction[1]. In patients with chronic bilateral and unilateral ureteral 
obstruction, abnormalities in almost all aspects of renal function have been observed after relief of the obstruction[2]. While POD is due partly to defective reabsorption of water and solute as a result of impaired distal tubular function, it is primarily due to fluid overload accumulated during the period of obstruction compounded by the osmotic effect of retained solute[3]. Thus, the mechanism for POD is generally the physiologic excretion of accumulated solutes and free water from volume expansion that occurred during obstruction[4]. Sodium, urea, and free water are eliminated and the diuresis subsides after homeostasis is achieved[1]. Pathologic POD, characterized by inappropriate renal handling of water and/or solutes can ensue due to downregulation of sodium transport channels, downregulation of aquaporin channels, poor responsiveness of the collecting duct to vasopressin, or altered regulation of atrial natriuretic peptide[5-7]. These changes have been shown to occur with bilateral ureteral obstruction in rats for only $\mathbf{2 4}$ hours and can result in a profound diuresis and natriuresis by disrupting the medullary interstitial solute gradient[2,5,6]. Thus, physiologic POD occurs as a natural response to excreting excess solute and free water, whereas pathologic POD results from the inappropriate diuresis of water and electrolytes, which we identified as those patients who required additional intravenous fluids to maintain homeostasis against fluid losses.

It has previously been stated that significant POD does not occur after the release of unilateral ureteral obstruction in the presence of a normal contralateral renal unit[3]. There have been 4 case reports of POD following relief of unilateral urinary obstruction with a normal contralateral kidney occurring in 3 neonates and a 27 year old[1,3]. At our 
institution, we have experienced multiple episodes of POD after relief of unilateral obstruction in patients with a normal contralateral kidney. We sought to determine the incidence and characteristics of pathologic POD that occurs after relief of unilateral ureteropelvic junction obstruction (UPJO) in the presence of a normal contralateral kidney. We hypothesized that this was a rare, but clinically significant phenomenon.

\section{Methods:}

After receiving Institutional Review Board approval, we retrospectively reviewed patients up to 18 years old with UPJO treated with pyeloplasty or percutaneous nephrostomy tube (PCN) placement at our institution from 7/1/2010 to 9/30/2017 to determine the rate of POD. Patients were identified based on pyeloplasty CPT code (50400, $50405,50544)$ regardless of presentation. We excluded patients with a functionally solitary kidney, including those patients with multicystic dysplastic kidneys, or those who underwent bilateral pyeloplasty or bilateral PCN placement. Patients with other renal abnormalities with two functional renal units, such as horseshoe kidneys, vesicoureteral reflux, and megaureter were included.

The primary outcome was the incidence of POD following relief of unilateral obstruction in the presence of a normal contralateral kidney. Since POD is not defined in children, we used an arbitrary, but clinically useful definition of urine output (UO) of $>300 \%$ of expected urine output in patients with a normal contralateral kidney observed within 412 hours immediately following the procedure. This increased urine output was only considered as such if it averaged $>\mathbf{3 0 0} \%$ for the duration of the time interval since 
surgery. Expected urine output was calculated depending on the age of the child (e.g. infants may make up to $2 \mathrm{ml} / \mathrm{kg} / \mathrm{hr}$, children $1 \mathrm{ml} / \mathrm{kg} / \mathrm{hr}$, and teenagers 0.5 $\mathrm{ml} / \mathrm{kg} / \mathrm{hr}$ ). This longer time frame was used to attempt to identify those with pathologic $P O D$ requiring additional intravenous fluid rather than children with physiologic $P O D$ or children undergoing natural diuresis of the increased volume of fluid they received intraoperatively. Resolution of POD was defined as diminution of polyuria and the ability of the child to take in adequate oral fluids to match urine output.

At our institution, standard rates for age of IVF are administered throughout the course of the procedure. Patients have a foley catheter in place overnight and are either left with an internal stent or a percutaneous nephrostomy that crosses the anastomosis without entering the bladder following their open pyeloplasty. Patients undergoing robotic pyeloplasty have a foley overnight and an internal stent. Patients are routinely placed on intravenous fluid at a rate of $1.5 x$ maintenance dextrose $5 \%$ half normal saline the night of their procedure. They are examined at the conclusion of the operative day, overnight and again the next morning following their procedure, allowing for several time interviews for evaluation. If excessive urine output is observed, nephrology is consulted to evaluate for potential pathologic post obstructive diuresis. In patients who developed pathologic POD, vital signs and urine output (UO) were closely monitored, and the nephrology service was consulted to help manage fluid and electrolyte replacement. Initial UO was defined as the urine output observed when nephrology was consulted due to POD. Once nephrology was consulted, intravenous fluid (IVF) would 
be increased to match output and may have artificially elevated urine outputs, so data obtained after nephrology involvement was not considered.

We collected data on age, gender, laterality of affected kidney, renal length, function, and drainage times. Data were based on either renal ultrasound, CT scan and MAG-3 renal scans obtained within 3 months prior to intervention. In those who experienced POD, additional information was collected on time to resolution of POD, electrolyte abnormalities during diuresis, and, if available, the amount of urine produced by each kidney prior to nephrologic intervention.

Differential kidney size was calculated by subtracting the size of the unaffected kidney from the affected kidney. The ratio of differential kidney size was calculated by dividing the affected kidney size by the unaffected kidney size. Data analysis involved MannWhitney $\mathrm{U}$ tests for continuous data and Fisher's exact tests for categorical data. A critical $p \leq 0.05$ was used (Stata 10.1 StataCorp, College Station, TX, USA).

\section{Results:}

Over an 8-year period, 429 children with UPJO underwent pyeloplasty or PCN placement at our institution. Of this group, $396(92.3 \%)$ had a normal contralateral kidney. All patients had primary UPJO, except for $2(0.5 \%)$ who had recurrent UPJO. To initially manage their UPJO, 272 (68.7\%) patients underwent open pyeloplasty, 98 (24.7\%) underwent robotic pyeloplasty, and $26(6.6 \%)$ underwent PCN placement. Seven children (1.8\%) developed POD within 4 to 12 hours after relief 
of obstruction (4 after pyeloplasty and 3 after PCN placement). Of those who developed POD, median age at intervention was 1.7 years (range 11 days - 18 years) and median weight was $11.4 \mathrm{~kg}$ (range 3.7 - $54.2 \mathrm{~kg}$ ). Those who developed POD were more likely to have grade 4 hydronephrosis compared to those who did not develop POD (100\% vs. $57.3 \%, p=0.05)$. Stated in another way, the risk of developing POD in a kidney with grade 4 hydronephrosis was $3.0 \%$ (7/230), compared to $0.0 \%$ in kidneys with lower grades of hydronephrosis $(p=0.04)$. In addition, in those patients where differential urine output could be determined $(\mathbf{n}=5)$, the obstructed kidney's output was on average 9.5 times that of the normal contralateral kidney.

Children who developed POD tended to have a larger affected kidney (size differential: $+4.4 \mathrm{~cm}$ vs. $+1.4 \mathrm{~cm}, \mathrm{p}=0.02$, ratio: 1.8 vs. $1.2, \mathrm{p}=0.01$ ), and undergo PCN placement prior to definitive surgical correction $(42.9 \%$ vs. $5.9 \%, p<0.01)$ (Table 1$)$. There was no significant difference in age, gender, affected kidney laterality, affected kidney function, or affected kidney drainage times between those who developed POD and those who did not. Half (3/6) of the children who developed POD were hypertensive on initial systolic and diastolic blood pressure monitoring pre-operatively on the day of their procedure. One patient did not have pre-operative blood pressure data and the remainder were normotensive.

Three patients who developed POD had PCN placed prior to definitive surgical correction of their UPJO. One patient underwent a PCN due to persistent abdominal pain and a very large kidney occupying the majority of the abdominal cavity. A second 
patient underwent a PCN due to abdominal swelling and a palpable mass from her enlarged kidney. A third patient underwent PCN due to a calyceal rupture believed to have occurred during birth due the combination of UPJO and a traumatic birth due to shoulder dystocia. Imaging obtained following birth revealed a perinephric urinoma prompting urinoma drainage and nephrostomy tube placement.

Patients who developed POD were managed with additional intravenous (IV) fluids and frequent electrolyte monitoring as determined by the nephrologist. Median UO at diagnosis of POD was $5.9 \mathrm{ml} / \mathrm{kg} / \mathrm{hr}$ (range 3.2 - 10.0). Five patients had PCN following their procedure, and two patients had indwelling stents. In those with PCN where UO could be differentiated between kidneys, median initial post-procedure UO from the affected side was $6.1 \mathrm{mg} / \mathrm{kg} / \mathrm{hr}$ (range 2.5 - 9.1) and $0.8 \mathrm{mg} / \mathrm{kg} / \mathrm{hr}$ (range 0.4 - 0.9) from the unaffected side (Figure 1). The median length of time to resolution of POD was 3 days (range 2-4 days). Electrolyte abnormalities occurred in 4 children (57.1\%). One patient developed acidosis (bicarbonate $12 \mathrm{mmol} / \mathrm{L}$ ) and lethargy that improved with IV fluid management. Hyponatremia developed in 2 (132 and $133 \mathrm{mmol} / \mathrm{L}$ ), hypokalemia in 1 ( $2.9 \mathrm{mmol} / \mathrm{L})$, hypomagnesemia in 0, hypophosphatemia in 1 (4.4 $\mathbf{m g} / \mathbf{d L}$ ), and hypoglycemia in 1 (43 $\mathbf{m g} / \mathbf{d L}$ ) (Table 2). No patients were observed to have problems at a median follow up of 14 months (IQR 4.5-29 months). 


\section{Discussion:}

While rare, $\mathrm{POD}$ is a significant clinical concern when it occurs. Pathologic diuresis can lead to hypovolemia from excess water loss and electrolyte abnormalities can develop due to salt or potassium wasting[1]. In Infants and young children, it would be difficult to correct this diuresis with free access to fluids as they may not have access to fluids to drink to thirst. Without close observation, a massive, sustained and life-threatening diuresis can ensue[8]. Close monitoring and careful fluid and electrolyte replacement are indicated in these patients[9]. The type and amount of IV fluid administered should be altered based on the patient's clinical status and electrolyte imbalances[10].

The etiology of POD following unilateral obstruction in the setting of a normal contralateral kidney is likely multifactorial. It has been hypothesized to occur due to a damaged distal nephrons which are unable to reabsorb water appropriately due to the retained normal glomerular filtration in the obstructed kidney in combination with the absence of a normal concentrating mechanism[1]. Further, POD following unilateral obstruction may be mediated by pressure atrophy of tissue adjacent to the collecting system resulting in more tubular damage than glomerular damage[3]. Additionally, the neonatal kidney is somewhat protected from glomerular damage due to increased renovascular resistance. When tubular damage exceeds glomerular damage, there can be inappropriate loss of salt and water[3]. In the present study, we observe that larger kidneys with parenchymal thinning were particularly more likely to go into pathologic POD after relief of obstruction, supporting these hypotheses. 
In adults, vascular constriction mediated by angiotensin and other vasoactive agents results in damage to the entire kidney, decreasing both glomerular and tubular function and maintaining glomerulotubular balance[11]. Creating a situation where glomerular filtration remains relatively intact while tubular function is selectively impaired is hard to duplicate in a mature kidney, which is why diuresis following relief of unilateral ureteral obstruction is usually normal as the contralateral kidney is present and capable of excreting excess water and solute[3]. However, kidneys usually mature with respect to glomerular filtration by age 1-2[12]. Although 3 previously reported cases of POD in a unilaterally obstructed system occurred in neonates, one occurred in a 27 -year-old[1,3]. Three of seven children in our series were at least 4 years old and therefore reached renal maturity, raising doubts about this hypothesis is the sole etiology of this phenomenon.

Little is known about electrolyte abnormalities following relief of obstruction of a unilateral system with a normal contralateral kidney. The other case reports in the literature do not discuss postoperative electrolyte anomalies[1,3]. In this study, patients that had postprocedural electrolyte abnormalities could not be predicated due to small numbers of cases. One patient experienced systemic symptoms of lethargy, hypoglycemia and an anion gap metabolic acidosis, with the others having minor electrolyte disturbances. The lack of predictable electrolyte abnormalities occurring after POD make it difficult to identify a common cause of the observed POD but underlies the need for vigilant monitoring. 
This represents the second study to try to determine the prevalence of POD following relief of unilateral obstruction in the presence of a normal contralateral kidney. Bermeo et al. recently published a study citing a $30 \%$ incidence of post obstructive diuresis following pyeloplasty[13]. This number is vastly different from the number of cases of POD observed in this study and the few case reports in the literature[1,3]. Part of this may be due to patients with solitary kidneys being included in this study, as the authors do not report the number of patients included in their study with solitary kidneys[13]. Obstructions in solitary kidneys behave differently than obstructions in a single kidney with a healthy contralateral kidney. Additionally, the definition of post obstructive diuresis used in that study was $5 \mathrm{ml} / \mathrm{kg} / \mathrm{hr}$ for 2 consecutive hours[13]. This definition may be too broad and may be capturing patients with physiologic diuresis due to the increased amounts of fluid they received intraoperatively or in the immediate postoperative period. Comparatively, our study has a larger number of patients with a stricter definition of post-obstructive diuresis to identify those with pathologic POD. It is important to differentiate physiologic from pathologic $P O D$ as physiologic $P O D$ is selflimiting and generally lasts 24 hours or less, while pathologic POD generally lasts longer than 48 hours and can be exacerbated with excessive intravenous fluid replacement[14]. Future research should attempt to corroborate renal factors we observed to be associated with this phenomenon: grade 4 hydronephrosis, a significantly larger obstructed kidney, and symptoms requiring PCN prior to definitive surgical management.

There are several limitations to our study. Data were collected retrospectively, but with the rarity of POD after relief of unilateral renal obstruction it would make a prospective 
study of this phenomenon challenging. The small outcome event rate (only 7 outcome events) prohibits multivariable analysis of the risk factors found in this study, to compare which one is most significantly associated with the development of POD. Further, we did not make a distinction of physiologic or pathologic POD as it is hard to assess physiologic POD from a retrospective chart review. Other data that could not be included due to retrospective review such as estimated blood loss or degree of IVF resuscitation may confound results. Numerous urologists and nephrologists were involved in the management of each of these patients, making standardization of care difficult. In addition, the results may not be generalizable as this was a single institution study. Lastly, the arbitrary definition of of POD, especially in children makes this a difficult phenomenon to study.

POD is a theoretically life-threatening condition that can occur following relief of unilateral obstruction with a normal contralateral kidney. High risk patients undergoing pyeloplasty or PCN placement should be closely monitored following the procedure for development of post obstructive diuresis. Clinicians should aim to determine if this is a normal physiologic response to relief of obstruction due to increased intraoperative fluids or a pathologic response that could be lethal if not recognized. Laboratory evaluation of electrolytes and nephrology consultation should be considered in any case where observed UO greatly exceeds expected UO. 
Conclusion: POD defined as $>\mathbf{3 0 0} \%$ expected urine output between $\mathbf{4 - 1 2}$ hours postprocedure after resolution of unilateral UPJO with pyeloplasty or PCN with a normal contralateral kidney occurred in $1.8 \%$ of children, and in $3.0 \%$ of children with grade 4 hydronephrosis. Children should be carefully monitored following these procedures given the potential for significant dehydration and electrolyte disturbances. Factors associated with this phenomenon include grade 4 hydronephrosis, a comparatively larger obstructed kidney and symptoms requiring nephrostomy tube placement prior to definitive surgical management.

Conflict of Interest: None

Funding: None

Ethical approval: IRB approved study

\section{References:}

[1] Schlossberg SM, Vaughan ED. The mechanism of unilateral post-obstructive diuresis. The Journal of Urology 1984;131:534-6.

[2] Meldrum KK. Pathophysiology of Urinary Tract Obstruction. In: Wein AJ, Kavoussi LR, Partin AW, Peters CA, editors. Campbell-Walsh Urology. 11 ed., Philadelphia: 2016, pp. 1089-103. 
[3] Boone TB, Allen TD. Unilateral post-obstructive diuresis in the neonate. The Journal of Urology 1992;147:430-2.

[4] Howards SS. Post-obstructive diuresis: a misunderstood phenomenon. Journal of Urology 1973;110:537-40.

[5] Li C, Wang W, Kwon TH, Isikay L, Wen JG, Marples D, et al. Downregulation of AQP1, -2 , and -3 after ureteral obstruction is associated with a long-term urineconcentrating defect. Am J Physiol Renal Physiol 2001;281:F163-71. doi:10.1152/ajprenal.2001.281.1.F163.

[6] Li C, Wang W, Kwon T-H, Knepper MA, Nielsen S, Frøkiær J. Altered expression of major renal $\mathrm{Na}$ transporters in rats with bilateral ureteral obstruction and release of obstruction. Am J Physiol Renal Physiol 2003;285:F889-901. doi:10.1152/ajprenal.00170.2003.

[7] Kim SW, Lee J, Park JW, Hong JH, Kook H, Choi C, et al. Increased expression of atrial natriuretic peptide in the kidney of rats with bilateral ureteral obstruction. Kidney Int 2001;59:1274-82. doi:10.1046/j.1523-1755.2001.0590041274.x.

[8] Gibbons MD, Koontz WW. Obstructive uropathy and nephrogenic diabetes insipidus in infants. Journal of Urology 1979;122:556-9.

[9] Vaughan ED, Gillenwater JY. Diagnosis, characterization and management of post-obstructive diuresis. Journal of Urology 1973;109:286-92.

[10] Baum N, Anhalt M, Carlton CE, Scott R. Post-obstructive diuresis. Journal of Urology 1975;114:53-6.

[11] el-Dahr SS, Lewy JE. Urinary tract obstruction and infection in the neonate. Clin Perinatol 1992;19:213-22. 
[12] Arant BS. Postnatal development of renal function during the first year of life. Pediatr Nephrol 1987;1:308-13.

[13] Bermeo AMP, Zableh AMO, Castillo M, Niño JFP. Risk factors for postobstructive diuresis in pediatric patients with ureteropelvic junction obstruction, following open pyeloplasty in three high complexity institutions. Journal of Pediatric Urology 2018:1-10. doi:10.1016/j.jpurol.2018.01.017.

[14] Halbgewachs C, Domes T. Postobstructive diuresis: pay close attention to urinary retention. Can Fam Physician 2015;61:137-42. 
Figure 1: Overall and differential urine output $(\mathrm{ml} / \mathrm{kg} / \mathrm{hr})$ in patients who developed POD prior to nephrology referral. 
Table 1: Patient characteristics

\begin{tabular}{|l|c|c|c|}
\hline & $\begin{array}{c}\text { No POD } \\
\text { (N=389) }\end{array}$ & $\begin{array}{c}\text { POD } \\
\text { (N=7) }\end{array}$ & p - value \\
\hline Median Age, yrs (IQR) & $1.1(0.3-6.6)$ & $1.7(0.1-8.4)$ & 0.68 \\
\hline Sex, \# Female (\%) & $116(29.8 \%)$ & $3(42.9 \%)$ & 0.43 \\
\hline Side, \# Left (\%) & $234(60.2 \%)$ & $4(57.1 \%)$ & 0.99 \\
\hline \# of Duplex System (\%) & $9(2.3 \%)$ & $0(0 \%)$ & 0.99 \\
\hline $\begin{array}{l}\text { Median Split Function of } \\
\text { Affected Side, \% (IQR) }\end{array}$ & $49 \%(42 \%-53 \%)$ & $51 \%(39 \%-55 \%)$ & 0.66 \\
\hline $\begin{array}{l}\text { Median t1/2 of Affected } \\
\text { Side, min (IQR) }\end{array}$ & $51(27-105)$ & $31(19-59)$ & 0.61 \\
\hline $\begin{array}{l}\text { Grade of Hydronephrosis } \\
\text { of Affected Kidney Prior to } \\
\text { Intervention, \# (\%) }\end{array}$ & & & 0.05 \\
\hline $\mathbf{0}$ & $0(0.0 \%)$ & $0(0 \%)$ & \\
\hline $\mathbf{1}$ & $0(0 \%)$ & $0(0 \%)$ & \\
\hline $\mathbf{2}$ & $11(2.8 \%)$ & $0(0 \%)$ & \\
\hline \multicolumn{1}{|c|}{ Unknown } & $123(31.6 \%)$ & $0(0 \%)$ & \\
\hline $\begin{array}{l}\text { Median Size Differential of } \\
\text { Affected Compared to } \\
\text { Unaffected Kidney, cm } \\
\text { (IQR) }\end{array}$ & $223(57.3 \%)$ & $7(100.0 \%)$ & 0.02 \\
\hline $\begin{array}{l}\text { Median Size Ratio of } \\
\text { Affected to Unaffected } \\
\text { Kidney (IQR) }\end{array}$ & $32(18.8 \%)$ & $0(0 \%)$ & \\
\hline $\begin{array}{l}\text { Need for Nephrostomy } \\
\text { Tube Prior to Pyeloplasty, } \\
\text { \# (\%) }\end{array}$ & $1.4(+2.4$ to -0.8$)$ & $+4.4(+5.6$ to -2.5$)$ & \\
\hline
\end{tabular}


Table 2: Characteristics of POD after Relief of Unilateral Obstruction

\begin{tabular}{|c|c|c|c|c|c|c|c|}
\hline & 1 & 2 & 3 & 4 & 5 & 6 & 7 \\
\hline Age & 11 days & $1.4 \mathrm{mos}$ & $1.6 \mathrm{mos}$ & $1.7 \mathrm{yrs}$ & $4.0 \mathrm{yrs}$ & $12.8 \mathrm{yrs}$ & $18.4 \mathrm{yrs}$ \\
\hline Sex & M & M & M & $\mathrm{F}$ & M & $\mathrm{F}$ & $\mathrm{F}$ \\
\hline Side & $\mathrm{L}$ & $\mathrm{R}$ & $\mathrm{L}$ & $\mathrm{L}$ & $\mathrm{L}$ & $\mathrm{R}$ & $\mathrm{R}$ \\
\hline Split Function & $51 \%$ & $58 \%$ & $65 \%$ & $52 \%$ & $47 \%$ & $18 \%$ & $31 \%$ \\
\hline $\begin{array}{l}\text { Drainage Time } \\
\text { (min) }\end{array}$ & Flat curve & 41 & $\begin{array}{l}\text { Flat } \\
\text { curve }\end{array}$ & 111 & $\begin{array}{l}\text { Flat } \\
\text { curve }\end{array}$ & $\begin{array}{l}\text { Flat } \\
\text { curve }\end{array}$ & 20 \\
\hline $\begin{array}{l}\text { Hydronephosis } \\
\text { Grade }\end{array}$ & 4 & 4 & 4 & 4 & 4 & 4 & 4 \\
\hline $\begin{array}{l}\text { Affected Kidney } \\
\text { Size (cm) }\end{array}$ & 9.22 & 8.2 & 8.4 & 6.0 & 14.5 & 28.5 & 10.8 \\
\hline $\begin{array}{l}\text { Kidney Size } \\
\text { Differential }\end{array}$ & -4.4 & -3.6 & -4.6 & -1.4 & -6.5 & -17.6 & 0.3 \\
\hline $\begin{array}{l}\text { Differential Kidney } \\
\text { Size Ratio }\end{array}$ & 1.9 & 1.8 & 2.2 & 1.1 & 1.8 & 2.6 & 1.0 \\
\hline Preoperative HTN & Yes & $\mathrm{N} / \mathrm{A}$ & No & No & Yes & No & Yes \\
\hline Procedure & $\mathrm{N}$ & OP & $\mathrm{OP}$ & $\mathrm{OP}$ & $\mathrm{N}$ & $\mathrm{N}$ & $\mathrm{RP}$ \\
\hline NSAID Use & No & No & No & No & No & No & $\begin{array}{l}1 \text { dose of } \\
\text { ketorolac } \\
\text { after } \\
\text { pyeloplasty }\end{array}$ \\
\hline HCTZ Use & No & No & No & No & No & No & No \\
\hline \multicolumn{8}{|l|}{$\begin{array}{l}\text { Initial urine output } \\
\text { after intervention } \\
(\mathrm{ml} / \mathrm{kg} / \mathrm{h})\end{array}$} \\
\hline Overall & 7.2 & 6.7 & 3.4 & 3.2 & 6.7 & 10 & 4.9 \\
\hline Affected kidney & 6.8 & 6.1 & 2.5 & -- & 5.9 & 9.1 & -- \\
\hline Unaffected kidney & 0.4 & 0.6 & 0.9 & -- & 0.8 & 0.9 & -- \\
\hline $\begin{array}{l}\text { Time to Resolution } \\
\text { of POD }\end{array}$ & 2 & 4 & 3 & 3 & 2 & 4 & 2 \\
\hline Hyponatremia & $C^{2}$ & & & & $\mathrm{x}$ & & $\mathrm{x}$ \\
\hline Hypokalemia & +2 & & & & & & $x$ \\
\hline \multicolumn{8}{|l|}{ Hypomagnesemia } \\
\hline Hypophosphatemia & 7 & & $x$ & & & & \\
\hline Hypoglycemia & & & & $x$ & & & \\
\hline Acidosis & & & & $x$ & & & \\
\hline Lethargy & & & & $x$ & & & \\
\hline
\end{tabular}

Abbreviations: $F=$ female, $M=$ male, $L=$ left, $R=$ right, $H T N=$ hypertension, $O P=$ open pyeloplasty, $\mathrm{RP}=$ robotoic pyeloplasty, $\mathrm{N}=$ nephrostomy tube, NSAID=nonsteroidal antiinflam matory drug, HCTZ (hydrochlorothiazide) 


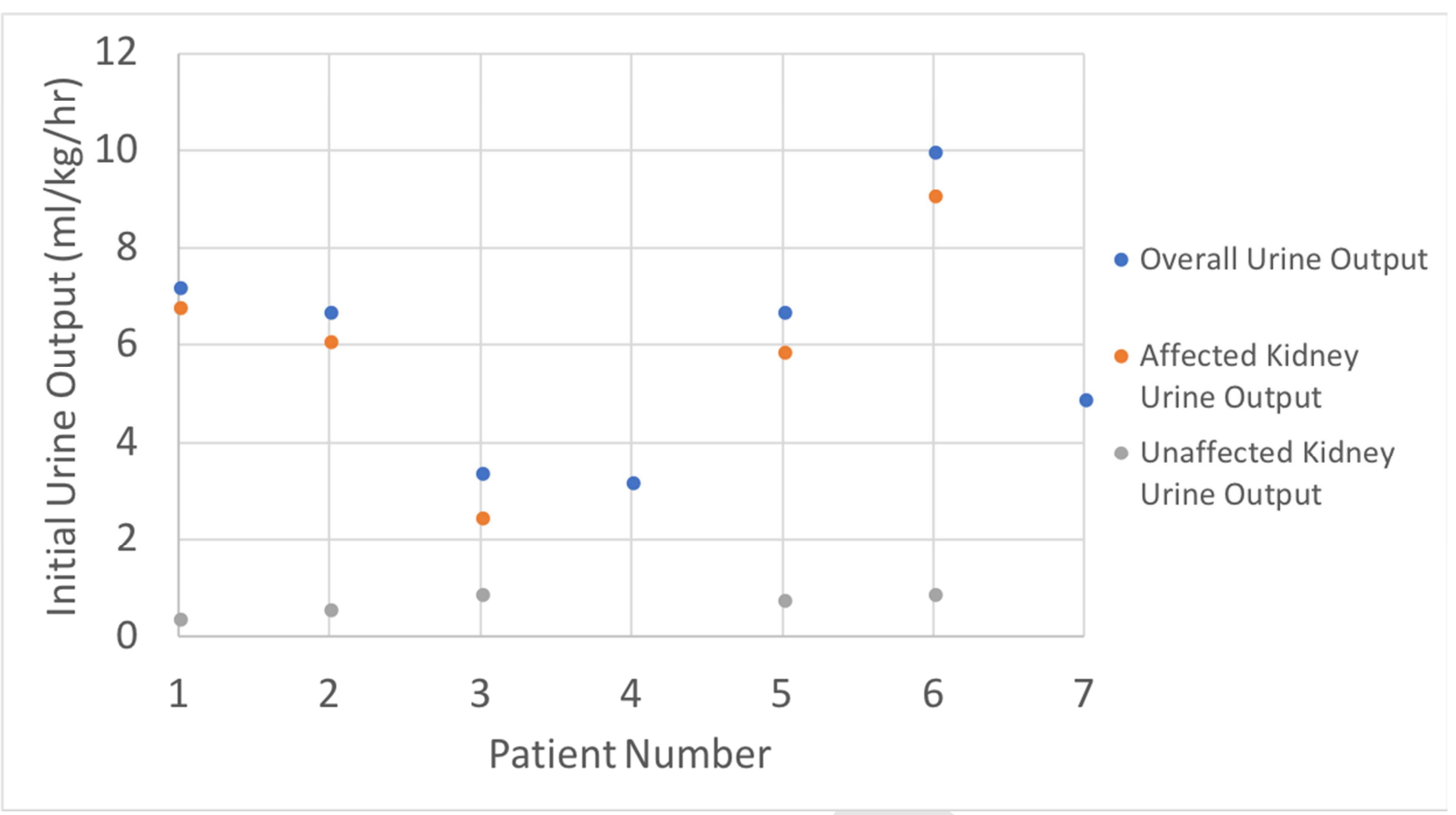


Extended Summary Table: Predictors of Post Obstructive Diuresis

\begin{tabular}{|l|c|c|c|}
\hline \multicolumn{1}{|c|}{$\begin{array}{c}\text { No POD } \\
\text { (N=389) }\end{array}$} & $\begin{array}{c}\text { POD } \\
\text { (N=7) }\end{array}$ & p - value \\
\hline $\begin{array}{l}\text { Grade of Hydronephrosis } \\
\text { of Affected Kidney Prior to } \\
\text { Intervention, \# (\%) }\end{array}$ & & & \\
\hline \multicolumn{1}{|c|}{$\mathbf{3}$ or lower } & $166(42.7 \%)$ & $0(0 \%)$ & 0.04 \\
\hline $\begin{array}{l}\text { Median Size Differential of } \\
\text { Affected Compared to } \\
\text { Unaffected Kidney, cm } \\
\text { (IQR) }\end{array}$ & $223(57.3 \%)$ & $7(100.0 \%)$ & 0.02 \\
\hline $\begin{array}{l}\text { Median Size Ratio of } \\
\text { Affected to Unaffected } \\
\text { Kidney (IQR) }\end{array}$ & $1.4(+2.4$ to -0.8) & $+4.4(+5.6$ to -2.5) & \\
\hline $\begin{array}{l}\text { Need for Nephrostomy } \\
\text { Tube Prior to Pyeloplasty, } \\
\text { \# (\%) }\end{array}$ & $23(5.9 \%)$ & $3(42.9 \%)$ & 0.01 \\
\hline
\end{tabular}

